\title{
KEWENANGAN HUKUM ASEAN DALAM MEMBUAT PERJANJIAN INTERNASIONAL DENGAN PIHAK EKSTERNAL BERDASARKAN PIAGAM ASEAN
}

\author{
Natalia Yeti Puspita \\ Fakultas Hukum Universitas Katolik Indonesia Atma Jaya \\ Email: natalia.yeti@atmajaya.ac.id
}

\begin{abstract}
Since the entry into force of the ASEAN Charter in 2008, it is widely said that ASEAN has moved from a loose organization to a rule-based one based on. As an international organization which is distinguished by its member states, ASEAN has legal authority to conclude an international agreement with external party. This is governed in the Article 3 Juncto Article 41 (7) ASEAN Charter. In order to examine this provision, has been produced the 2011 Rules of Procedure for the Conclusion of International Agreements by ASEAN. Unfortunately in practice, the implementation of this provision is affected by the strong presence of the principle of state sovereignty held by each ASEAN member states. In this paper, the writer will analysis on ASEAN Legal Authority in Conclusion of International Agreement with External Party Based on ASEAN Charter.
\end{abstract}

Keywords: ASEAN's legal authority, conclusion of international agreement, ASEAN Charter.

\begin{abstract}
Abstrak
Sejak Piagam ASEAN dinyatakan berlaku pada tahun 2008, dapat dikatakan bahwa ASEAN telah berubah dari sebuah organisasi kawasan yang longgar menjadi sebuah organisasi yang berdasarkan aturan. Sebagai sebuah organisasi internasional yang mandiri dan dibedakan dengan negara anggotanya, ASEAN mempunyai kewenangan hukum untuk membuat perjanjian internasional dengan pihak eksternal. Hal ini diatur dalam Pasal 3 Juncto Pasal 41 ayat (7) Piagam ASEAN. Untuk melaksanakan ketentuan tersebut dikeluarkanlah the 2011 Rules of Procedure for the Conclusion of International Agreements by ASEAN. Akan tetapi dalam praktik, pelaksanaan ketentuan ini dipengaruhi oleh kuatnya keberadaan prinsip kedaulatan negara yang dianut oleh masing-masing negara anggota ASEAN. Dalam tulisan ini, penulis akan menganalisis mengenai kewenangan hukum ASEAN dalam membuat perjanjian internasional dengan pihak eksternal berdasarkan Piagam ASEAN.

Katakunci: kewenangan hukum ASEAN, pembuatan perjanjian internasional, Piagam ASEAN
\end{abstract}




\section{A. Pendahuluan}

Association of South East Asian Nations (ASEAN) adalah sebuah organisasi internasional regional di kawasan Asia Tenggara, yang didirikan pada tahun 1967 dengan Deklarasi Bangkok (Deklarasi ASEAN) sebagai dasar hukum pembentukannya (Benny Teh Cheng Guan, 2004:hlm.71). Dalam kurun waktu antara tahun 1967 hingga tahun 2008, peranan ASEAN sebagai sebuah organisasi internasional yang mandiri dan dibedakan dengan negara-negara anggotanya tidaklah begitu kentara, keberadaan ASEAN lebih mirip layaknya sebuah "klub" atau paguyuban.

Kondisi ASEAN yang demikian unik ini membuat ASEAN dipertanyakan mengenai personalitas hukumnya terutama dalam hal kewenangannya membuat perjanjian internasional dengan pihak eksternal (Henry G.Schermers and Niels M.Blokker, 2003: hlm.1071-1084). Banyak perjanjian internasional yang dibuat oleh ASEAN selama kurun waktu tersebut menyerupai sebuah perjanjian multilateral dari negara-negara anggotanya dengan pihak eksternal, sedangkan ASEAN sebagai sebuah organisasi internasional hanya sebagai “penonton”nya saja. Seperti contohnya, Perjanjian Internasional yang dibuat antara ASEAN dan EEC (European Economic Community) pada tanggal 7 Maret 1980, di pihak ASEAN perjanjian tersebut ditanda-tangani secara sendiri-sendiri oleh negaranegara anggota ASEAN sedangkan di pihak EEC ditanda-tangani oleh Presiden Dewan EEC sebagai perwakilan EEC (Damos Dumoli, 2011: hlm.8). Jikapun terdapat perjanjian internasional yang ditandatangani oleh ASEAN sebagai sebuah organisasi internasional dan mengikat negara-negara anggotanya, tindakan ASEAN ini oleh negara anggotanya dianggap menyimpang dari praktik hukum perjanjian Internasional.

Dengan ditetapkannya ASEAN Charter (Piagam ASEAN) sebagai statuta dasar ASEAN menggantikan Deklarasi ASEAN pada tanggal 15 Desember 2008 di Thailand pada saat pertemuan ke-14 Kepala Negara ASEAN (Termsak 
Chalermpalanupap, 2009: hlm.178), telah secara de jure mengubah ASEAN dari organisasi kawasan yang longgar menjadi sebuah organisasi yang berdasarkan aturan (Eddy Pratomo, 2009: hlm 63). Perubahan Deklarasi ASEAN menjadi Piagam ASEAN tentu membawa makna logis dan akibat hukum terhadap pandangan ASEAN dan negara-negara anggotanya mengenai personalitas hukum (legal personality) yang dimiliki oleh ASEAN terutama dalam kaitannya dengan kewenangannya membuat perjanjian internasional dengan pihak eksternal.

Dengan ditetapkannya ASEAN Economic Community pada akhir tahun 2015 (Fuat Albayumi, 2012: hlm. 4), pemahaman mengenai kewenangan hukum ASEAN dalam membuat perjanjian internasional perlu mendapatkan perhatian lebih, hal ini dimaksudkan untuk mencegah terjadinya ultra vires pembuatan perjanjian internasional antara ASEAN dengan pihak eksternal. Berdasarkan hal tersebut, maka dalam tulisan kali ini penulis akan memaparkan lebih dalam mengenai kewenangan hukum ASEAN dalam membuat perjanjian internasional dengan pihak eksternal berdasarkan Piagam ASEAN.

\section{B. Personalitas Hukum ASEAN Sebagai Subyek Hukum Internasional}

1. ASEAN sebagai Sebuah Organisasi Internasional Regional

Regionalisme tidak hanya terjadi kawasan Eropa, Amerika dan Afrika saja, melainkan juga terjadi di kawasan Asia. ASEAN didirikan di kawasan Asia Tenggara pada tanggal 8 Agustus 1967 ditengah situasi regional dan internasional yang sedang berubah (Bambang Cipto, 2007: hlm.13). ASEAN tidak terbentuk dalam sebuah ruang kosong, sebaliknya telah didahului dengan upaya pembentukan organisasi regional yang lebih terbatas ruang lingkup keanggotaannya (Bambang Cipto, 2007: hlm.13). Sebelum terbentuknya ASEAN tahun 1967, negara-negara Asia Tenggara telah melakukan berbagai upaya untuk menggalang kerjasama regional baik yang bersifat intra maupun ekstra kawasan seperti Association of Southeast Asia (ASA), Malaya, Philippina, Indonesia (MAPHILINDO), South East Asian 
Ministers of Education Organization (SEAMEO), South East Asia Treaty Organization (SEATO) dan Asia and Pacific Council (ASPAC) (Kementerian Luar Negeri Republik Indonesia, 2008: hlm.8).

ASEAN pada awal mulanya dibentuk oleh perwakilan lima negara yaitu Indonesia, Malaysia, Singapura, Thailand, dan Philipina yang ditandai dengan ditandatanganinya Deklarasi Bangkok (ASEAN) (Djauhari Oratmangun, 2009: hlm.187-189). Organisasi ini bertujuan meningkatkan pertumbuhan ekonomi, kemajuan sosial, dan pengembangan kebudayaan negara-negara anggotanya, serta memajukan perdamaian di tingkat regional yang masih pada tahap kooperatif dan belum bersifat integratif (Kementerian Luar Negeri Republik Indonesia, 2008: hlm.8). Sejak tahun 1967 sampai dengan tahun 2008, interaksi negara-negara ASEAN berlandaskan pada Deklarasi Bangkok yang pada hakikatnya merupakan suatu pernyataan politik (political statement) yang tidak mengikat hak dan kewajiban negara anggota maupun organisasi atas dasar hukum/konstitusi (Elfia Farida, 2009: hlm.1). Sejak tahun 2008, ASEAN telah berubah menjadi sebuah organisasi antar pemerintah, dengan diratifikasinya Piagam ASEAN oleh seluruh negara anggota ASEAN.

Sebelum berlakunya Piagam ASEAN, ASEAN sering dipertanyakan tentang statusnya sebagai sebuah organisasi internasional. Adapun alasannya adalah sebagai berikut.

a. Di luar dari kebiasaan internasional yang ada, ASEAN dibentuk pertama kali pada tahun 1967 dengan sebuah deklarasi. Sebagaimana yang kita ketahui bahwa deklarasi bersifat softlaw artinya kekuatan hukum dari sebuah deklarasi tidaklah bersifat mengikat secara hukum bagi negaranegara anggotanya.

b. Sebuah organisasi internasional harus memiliki sebuah sekretariat organisasi yang menjalankan fungsi sehari-hari seperti fungsi administratif, 
penelitian, informasi. Ketentuan ini tidak bisa dipenuhi oleh ASEAN, karena dari kurun waktu tahun 1967 sampai dengan tahun 1976, ASEAN tidak memiliki sekretariat organisasi..

Ketiadaan Sekretariat dan juga di tambah status Deklarasi ASEAN waktu itu yang tidak mengikat negara anggotanya, membuat ASEAN sebelum berlakunya Piagam ASEAN telah kehilangan legitimasinya sebagai sebuah organisasi internasional. Pada KTT ke-1 ASEAN di Bali, tahun 1976, para Menteri Luar Negeri ASEAN menandatangani Agreement on the Establishment of the ASEAN Secretariat. Sekretariat ASEAN berfungsi sejak tanggal 7 Juni 1976, dikepalai oleh seorang Sekretaris Jenderal (Kementerian Luar Negeri Republik Indonesia, 2008: hlm.8). Dengan dibentuknya Sekretariat ASEAN maka ASEAN dapat dikatakan telah mendapatkan status yang sah sebagai sebuah organisasi internasional.

2. Personalitas Hukum ASEAN berdasarkan Piagam ASEAN

Organisasi internasional publik didirikan dengan suatu perjanjian internasional dan beroperasi atas dasar suatu persetujuan, rekomendasi dan kerja sama bukan paksaan (Sumaryo Suryokusumo, 1990: hlm. 106). Suatu organisasi internasional yang dibentuk melalui suatu perjanjian dengan bentuk instrumen pokok apapun akan memiliki suatu personalitas hukum di dalam hukum internasional. Personalitas hukum ini penting bagi suatu organisasi internasional agar dapat menjalankan fungsinya dengan baik seperti dalam hal membuat kontrak, membuat perjanjian dengan negara lain atau mengajukan tuntutan dengan negara lainnya (Sumaryo Suryokusumo, 1990: hlm. 110). Tanpa adanya personalitas hukum maka suatu organisasi internasional tidak akan mampu untuk melakukan tindakan yang bersifat hukum. Untuk mencapai tujuan sebagai suatu kesatuan, organisasi internasional harus mempunyai kemampuan untuk melaksanakannya atas nama semua negara anggotanya, tindakan organisasi ini dijamin oleh hukum internasional 
(Sumaryo Suryokusumo, 1990: hlm. 110). Terdapat hubungan antara personalitas hukum dan kapasitas hukum seperti dikemukakan oleh Weissberg berikut ini,

An entity which exercise international rights and is bound by international obligations, in short which has international legal capacity, is one which is endowed with international legal personality (Sumaryo Suryokusumo, 1990: hlm. 110 dan Guenter Weissberg, 1961: hlm. 23).

Selain itu, walaupun personalitas hukum tidak dicantumkan dalam instrument pokok organisasi internasional, sebagai subyek hukum internasional, organisasi internasional tidak perlu kehilangan personalitas hukum karena organisasi internasional akan mempunyai kapasitas untuk melakukan prestasi hukum sesuai dengan aturan dan prinsip-prinsip Hukum Internasional.

Berkaitan dengan personalitas hukumnya sebagai organisasi internasional, maka organisasi internasional mempunyai hak dan kewenangan hukum sebagai berikut:

a. The right to enter into international agreements with nonmember states on matter within the organization's province. Treaties conclude by the organization have all the legally binding effects of international treaties proper;

b. The right to immunity from jurisdiction of State courts for acts and activities performed by the organization;

c. The right to protection for all the organization's agents acting in the territory of a third state in their official capacity as international civil servants;

d. The right to bring an international claim with a view to obtaining reparation for any damage caused member states or by third States to assets of the organization or to its officials 
acting on behalf of the organization (Antonio Cassese, 2005:

hlm. 138-139).

Pemberian personalitas hukum terhadap organisasi internasional tidak terlepas dari keberadaan organisasi internasional itu sendiri sebagai salah satu subyek hukum internasional. Organisasi Internasional diakui sebagai subyek hukum internasional dengan dasar hukum sebagai berikut:

a. The Advisiory Opinion of International Court of Justice ((ICJ) dalam kasus "Reparation for Injuries Suffered in the Service of the United Nations case tahun 1949” ;

b. International Court of Justice Advisory Opinion in Interpretation of the Agreement of 25 March 1951 between WHO and Egypt” pada tahun 1980.

Sebagai subyek hukum internasional, organisasi internasional akan mempunyai hak dan kewajiban berdasarkan hukum internasional. Malcolm N. Shaw QC menyatakan bahwa, "Once this is (legal personality) established, they (international organization) become subjects of international law and thus capable of enforcing rights and duties upon international plane as distinct from operating merely within the confines of separate municipal jurisdiction” (Malcom N. Shaw QC, 2003: hlm.1187). Mahkamah Internasional telah memberikan pertimbangan bahwa "International Organization are subjects of international law and, as such, are bound by any obligations incumbent upon them under general rules of international law...” (Henry G. Schemers \& Niels M.Blokker, 2003: hlm. 996).

Ian Brownlie berpendapat bahwa terdapat tiga atribut yang menentukan apakah suatu organisasi internasional dapat dikatakan memiliki personalitas hukum yaitu, (1) Perhimpunan yang bersifat permanen dengan tujuan yang sah dan memiliki organ-organ kelengkapan, (2) pemisahan fungsi dan kewenangan hukum antara organisasi yang bersangkutan dan anggota- 
anggotanya, serta (3) terdapat kewenangan hukum yang dilaksanakan berdasarkan hukum internasional (Ian Brownlie, 1998: hlm. 679-680).

Simon Chestermen berpendapat bahwa ASEAN sebagai sebuah organisasi internasional memperoleh personalitas hukumnya berdasarkan “Will Theory” (Simon Chesterman, 2010: hlm.202). Will theory adalah sebuah teori yang menyatakan bahwa personalitas hukum dari sebuah organisasi internasional diberikan berdasarkan kehendak para pendirinya (Simon Chesterman, 2010: hlm.202). Adanya will theory dalam ASEAN dapat dilihat dari bunyi Pasal 3 Piagam ASEAN yang menyatakan bahwa ASEAN sebagai sebuah organisasi antar pemerintah dengan ini diberikan status hukum”.

Berdasarkan uraian tersebut di atas kita dapat mengetahui bahwa ASEAN sebagai sebuah organisasi internasional mempunyai personalitas hukum yang sah berdasarkan hal berikut ini:

a. ASEAN adalah organisasi yang bersifat permanen dengan tujuan yang sah dan mempunyai organ-organ kelengkapannya. Hal ini dapat dilihat isi Deklarasi ASEAN sebagai dasar pembentukan ASEAN dan dibentuknya Sekretariat ASEAN pada tahun 1976;

b. Pemisahan fungsi dan kewenangan hukum antara ASEAN dan negaranegara anggotanya dapat tercapai setelah dikeluarkannya 2011 Rules of Procedure for The Conclusion of International Agreements by ASEAN. Prosedur tentang pembuatan perjanjian internasional oleh ASEAN sebagai entitas yang mandiri dan dibedakan dari negara anggotanya akan dijelaskan dalam bab tersendiri dalam tulisan ini;

c. ASEAN melaksanakan kewenangan hukumnya berdasarkan hukum internasional. Hal ini dapat dilihat dari kewenangan ASEAN dalam membuat perjanjian internasional dengan pihak lain. ASEAN dalam berbagai kesempatan telah menandatangani Nota kesepahaman (MOU) (Bryan A. Garner, ed., 2004: hlm. 924) dengan pihak lain, seperti 
contohnya: ASEAN-China MOU on Cultural Cooperation, Bangkok $3^{\text {rd }}$ August 2005 yang ditandatangani oleh Sekretaris Jenderal ASEAN dan MOU between the Governmnets of the Member Countries of the ASEAN and the Government of Australia on the ASEAN-Australia Economic Cooperation Programme (AAECP) Phase III (Bangkok, 27 $7^{\text {th }}$ July 1994) yang ditandatangani oleh H.E.Dr.Surin Pitsuwan, Deputy Minister of Foreign Affairs, Acting Minister of Foreign Affairs of Thailand (Damos Dumoli, 2010: hlm 55).

ASEAN sebagai sebuah organisasi internasional telah menyatakan secara eksplisit di dalam instrumen pokoknya mengenai personalitas hukum yang dimilikinya. Personalitas hukum ASEAN dalam kewenangannya membuat perjanjian internasional ditegaskan lebih lanjut di dalam Pasal 41 ayat (7) Piagam ASEAN yang menyatakan bahwa,

ASEAN dapat menandatangani perjanjian-perjanjian dengan negara-negara atau organisasi-organisasi dan lembagalembaga sub-kawasan, kawasan dan internasional. Prosedur pembuatan perjanjian dimaksud akan diatur lebih lanjut oleh Dewan Koordinasi ASEAN melalui konsultasi dengan Dewan Komunitas ASEAN.

Adapun yang perlu mendapat catatan di sini adalah bahwa dengan dicantumkannya personalitas hukum ASEAN di dalam Pasal 3 Piagam ASEAN juncto Pasal 41 ayat (7) Piagam ASEAN maka bukan berarti sebelum ada Piagam ASEAN, ASEAN tidak memiliki personalitas hukum. Sebelum dikeluarkannya Piagam ASEAN, ASEAN telah memiliki personalitas hukum berdasarkan Deklarasi Bangkok atau lebih dikenal dengan Deklarasi ASEAN. Hanya saja dalam kurun waktu tersebut (masa berlakunya Deklarasi ASEAN), ASEAN tidak secara maksimal dan efektif melaksanakan personalitas hukumnya. Di dalam organisasi ASEAN, negara-negara anggota ASEAN lebih banyak memainkan peranan aktifnya dibandingkan ASEAN sebagai 
sebuah organisasi internasional. ASEAN telah menjadi sebuah organisasi yang tidak mandiri dan bebas.

\section{ASEAN Treaty Making Power Berdasarkan Piagam ASEAN}

\section{Kewenangan Hukum ASEAN dalam Membuat Perjanjian Internasional}

Sebagai sebuah organisasi internasional yang telah diberikan personalitas hukum seperti yang telah diuraikan di awal maka sudah seharusnya ASEAN bisa menunjukkan entitasnya yang mandiri dan dibedakan dengan negaranegara anggotanya terutama dalam melakukan tindakan hukumnya. Hal ini pun ditunjukkan secara ekslplisit dalam Pasal 41 ayat (7) Piagam ASEAN. Akan tetapi dalam praktik, perbuatan-perbuatan hukum yang dilakukan oleh ASEAN lebih ditujukan sebagai sebuah tindakan oleh negara-negara anggota secara collective, meskipun dalam ketentuannya ditulis sebagai tindakan ASEAN.

Adanya kondisi ini sedikit banyak dipengaruhi oleh sifat dan status organisasi yang dipilih oleh ASEAN yaitu sebagai sebuah organisasi intergovernmental. Hal tersebut terlihat jelas dalam Pasal 3 Piagam ASEAN. Sifat intergovernmental ASEAN terlihat nyata antara lain dalam struktur organisasi ASEAN. Dalam struktur organisasi ASEAN terdapat Dewan Koordinasi. Dewan Koordinasi ini terdiri dari para menteri luar negeri dari negara-negara anggota ASEAN dan mempunyai peranan penting dalam proses pembuatan perjanjian internasional oleh ASEAN. Selain itu posisi Sekretaris Jenderal ASEAN yang setara dengan menteri dan harus melaporkan kegiatannya kepada Dewan Koordinasi, padahal dalam sebuah organisasi internasional posisi Sekretaris Jenderal harusnya mempunyai posisi setara dengan Kepala Negara dan mempunyai kewenangan mandiri. Adanya hal-hal tersebut membuat ASEAN menjadi tidak independen dalam menjalankan fungsinya sebagai sebuah organisasi internasional. 
Berdasarkan pemaparan tersebut maka ketika berbicara mengenai kewenangan hukum ASEAN dalam membuat perjanjian internasional sebelumnya harus dimengerti definisi ASEAN terlebih dahulu yaitu 1). ASEAN sebagai entitas yang mandiri dan dibedakan dengan negara-negara anggotanya; 2) ASEAN sebagai “collective members" dari negara-negara anggotanya. Berikut ini akan dipaparkan lebih lanjut tentang hal tersebut:

a. ASEAN sebagai entitas yang mandiri dan dibedakan dari negara-negara anggotanya. Dalam konteks ini ASEAN bertidak sebagai sebuah subyek hukum internasional yang memiliki personalitas hukum. Sedangkan yang biasanya diberikan mandat untuk membuat perjanjian adalah Sekretaris Jenderal ASEAN. Tindakan hukum ini dilakukan untuk dan atas nama ASEAN sebagai sebuah organisasi internasional. Adapun perjanjian internasional yang telah dibuat ASEAN untuk kategori ini antara lain adalah sebagai berikut:

1) The Agreement relating to the Privileges and Immunities of the ASEAN Secretariat, 20 January 1979, between ASEAN Secretariat and Indonesia;

2) Agreement of Cooperation between the Association of Southeast Asian Nations (ASEAN) and the United Nations Educational, Scientific and Cultural Organization (UNESCO), Jakarta $12^{\text {th }}$ September 1998;

3) The Agreement on the Use and Maintenance of the Premises of the ASEAN Secretariat, $15^{\text {th }}$ March 1996, between ASEAN Secretariat and Indonesia;

4) Memorandum of Understanding between the Secretariat of the Association of Southeast Asian Nations (ASEAN) and the Secretariat of the United Nations Economic and Social Commission for Asia and the Pacific (ESCAP Secretariat); 
5) Arrangement between the ASEAN Secretariat and the United States Patent and Trademark Office (USPTO) on Cooperation in the Field of Intellectual Rights, $19^{\text {th }}$ April 2005;

6) Memorandum of Understanding between the Secretariat of the Association of Southeast Asian Nations (ASEAN) and the Shanghai Cooperation Organization (SCO), $21^{\text {st }}$ April 2005;

7) Memorandum of Understanding for Administrative Arrangements, this memorandum of understanding (MoU) will form the basis of Cooperation between the Association of Southeast Asian Nations Secretariat and Asian Development Bank (24 $4^{\text {th }}$ August 2006) (Damos Dumoli, 2011: hlm.13-14);

8) the 2009 Agreement on the Privileges and Immunities of the Association of Southeast Asian Nations Agreement (Center for International Law, National University of Singapore, http://cil.nus.edu.sg/category-search/: diakses tanggal 23 Oktober 2013)

9) the 2012 Agreement Between the Government of the Republic of Indonesia And the Association of Southeast Asian Nations (Asean) on Hosting and Granting Privileges and Immunities to the Asean Secretariat (Center for International Law, National University of Singapore, http://cil.nus.edu.sg/category-search/: diakses tanggal 23 Oktober 2013).

10) the 2012 Memorandum of Understanding Between the Association od Southeast Asian Nations and the Asian 
Development Bank (Center for International Law, National

University of Singapore, http://cil.nus.edu.sg/2012-

memorandum-of-understanding-between-the-association-

of-southeast-asian-nations-and-the-asian-development-

bank-signed-on-4-april-2012-in-phnom-penh-cambodia:

diakses tanggal 12 Desember 2013).

b. ASEAN sebagai collective members berarti ASEAN hanya sebagai wadah yang menaungi anggotanya. Segala keputusan tetap ditangan negara anggotanya. Damos Dumoli lebih jauh menyatakan, "The relations between ASEAN member countries and a third party where the status of each member country is as an independent subject of international law (Damos Dumoli, 2011: hlm.10). Dalam beberapa kasus perjanjian internasional yang dibuat ASEAN, terdapat beberapa perjanjian yang menggunakan kata ASEAN sebagai pihak perjanjian akan tetapi dalam praktiknya ditandatangani oleh masing-masing perwakilan negara negara anggota ASEAN. Adapun contoh perjanjiannya adalah sebagai berikut:

1) The 2011 ASEAN plus Three Emergency Rice Reserve Agreement (Center for International Law, National University of Singapore, http://cil.nus.edu.sg/2011/2011-asean-plus-three-emergency-rice-

reserve-agreement-signed-on-7-october-2011-in-jakarta-indonesia/:

diakses tanggal 12 Desember 2013). Perjanjian ini ditandatangani oleh para Menteri Pertanian dan Kehutanan masing-masing negara anggota ASEAN dengan Menteri Pertanian Negara Korea, Jepang dan China.

2) The 2010 Joint Declaration on ASEAN-UN Collaboration in Disasters Management. Bentuk perjanjian ini ditandatangani oleh Kepala Negara/pemerintahan dari masing-masing negara anggota ASEAN dengan Sekretaris Jenderal PBB (Center for International Law, National 
University of Singapore, http://cil.nus.edu.sg/2010/2010-jointdeclaration-on-asean-un-collaboration-in-disaster-management/: diakses tanggal 12 Desember 2013).

3) Second Protocol to Amend the Agreement on Trade in Goods of the Framework Agreement on Comprehensive Economic Cooperation between the Association of Southeast Asia Nations and the Peopleh of Republic China (Center for International Law, National University of Singapore, http://cil.nus.edu.sg/2010/2010-second-protocol-to-amendthe-agreement-on-trade-in-goods-of-the-framework-agreement-oncomprehensive-economic-cooperation-between-the-association-ofsoutheast-asian-nations-and-the-people of Republic Chinal: diakses tanggal 12 Desember 2013). Perjanjian ini ditandatangani oleh masingmasing Menteri Ekonomi negara anggota ASEAN dan Menteri Ekonomi Republik Rakyat Cina.

Berdasarkan contoh-contoh tersebut di atas kita dapat mengetahui bahwa ASEAN telah kehilangan legitimasinya sebagai sebuah organisasi internasional yang mandiri dan mempunyai personalitas hukum. Meskipun judul dari perjanjian dengan pihak eksternal tersebut menggunakan ASEAN sebagai subyek hukum akan tetapi isinya tetap saja ditandatangani oleh masing-masing negara anggota.

Kondisi tersebut di atas sebetulnya menjadi sebuah dilemma bagi ASEAN sebagai sebuah organisasi internasional. Dalam beberapa kasus pembuatan Perjanjian internasional, ASEAN sebagai sebuah organisasi internasional yang mandiri dalam hal ini diwakili oleh Sekretaris Jenderal ASEAN telah mencoba untuk berperan aktif untuk membuat perjanjian internasional dengan pihak eksternal, akan tetapi dalam praktiknya tindakan ASEAN tersebut dianggap sebagai tindakan ultravires oleh negara-negara anggotanya. Hal ini dikarenakan dalam praktik di ASEAN tidak dikenal 
pendelagasian kewenangan dari negara anggota kepada ASEAN untuk bertindak untuk dan atas nama negara anggota. Perjanjian internasional yang pernah dibuat oleh ASEAN dalam kasus ini terjadi dalam:

1) ASEAN-China MOU on Cultural Cooperation, Bangkok $3^{\text {rd }}$ August 2005 yang ditandatangani oleh Sekretaris Jenderal ASEAN.

2) MOU between the Governmnets of the Member Countries of the ASEAN and the Government of Australia on the ASEAN-Australia Economic Cooperation Programme (AAECP) Phase III (Bangkok, 27 July 1994) yang ditandatangani oleh H.E.Dr.Surin Pitsuwan, Deputy Minister of Foreign Affairs, Acting Minister of Foreign Affairs of Thailand (Damos Dumoli, 2010: hlm.55).

3) The 2009 MOU between ASEAN and the Government of the People's Republic of China on Cooperation in the Field of Non-Traditional Security Issued Signed on 18 November 2009 in Sieam Republic Cambodia yang ditandatangani oleh Sekretaris Jenderal ASEAN untuk dan atas nama negara-negara anggota ASEAN.

4) The 2012 MOU between the ASEAN and the Asian Development Bank yang ditandatangani pada tanggal 4 April 2012 di Phnom Penh Cambodia oleh Sekretaris Jenderal ASEAN untuk dan atas nama negara anggota ASEAN.

\section{Prosedur Pembuatan Perjanjian Internasional oleh ASEAN}

Berikut ini dipaparkan mengenai prosedur pembuatan perjanjian internasional oleh ASEAN sebelum dan sesudah berlakunya Piagam ASEAN.

a. Pembuatan Perjanjian Internasional oleh ASEAN Sebelum Berlakunya Piagam ASEAN

ASEAN sebagai subyek hukum internasional telah diberikan hak dan kewajibannya berdasarkan hukum internasional. Salah satu hak yang 
dimiliki oleh ASEAN adalah kemampuan dan kewenangannya sebagai sebuah organisasi internasional yang mandiri dan terpisah dari negaranegara anggotanya dalam membuat perjanjian internasional. Sejak dibentuknya Sekretariat ASEAN sebagai penanda legitimasi ASEAN sebagai organisasi internasional sampai dengan tahun 2008 sebelum berlakunya Piagam ASEAN, ASEAN telah melaksanakan kewenangannya dalam membuat perjanjian internasional dengan pihak lain baik itu dengan negara maupun organisasi internasional. Hanya saja dalam praktiknya ASEAN tidak mempunyai prosedur dan mekanisme yang lengkap, detail, jelas dan mempunyai kekuatan hukum dalam pembuatan perjanjian internasional oleh ASEAN secara mandiri sebagai organisasi internasional yang dibedakan dengan negara anggotanya. Adapun yang mempunyai tugas dan tanggung jawab utama dalam membuat perjanjian atau mengadakan hubungan internasional dengan pihak ekstern adalah ASEAN Ministerial Meeting sebagai plenary organ di ASEAN (Damos Dumoli, 2011: hlm.13-14). Damos Dumoli lebih lanjut menyatakan bahwa,

ASEAN Ministerial Meeting, which will formulate, when appropriate in consultation with relevant Ministers, guidelines for establishment of the machinery for the formalization, supervision, suspension or termination of negotiations with other governments and international organizations (Damos Dumoli, 2011: hlm.13-14).

Merujuk pada pernyataan tersebut, ASEAN Ministerial Meeting yang dihadiri oleh para menteri yang relevant dengan pokok materi yang dibahas dari negara anggota ASEAN bertanggung jawab penuh dalam pembuatan perjanjian internasional termasuk pengakhirannya dengan pemerintah dan organisasi internasional lain. Berdasarkan Deklarasi 
ASEAN, perjanjian internasional yang dibuat oleh ASEAN harus mendapatkan persetujuan dari menteri luar negeri. Dikatakan lebih lanjut oleh Damos Dumoli bahwa, "The Chairman of the ASEAN Standing Committee will be authorized to sign all agreements reached between ASEAN and third parties” (Damos Dumoli, 2011: hlm.13-14).

Ketiadaan aturan dan prosedur yang jelas telah membuat ASEAN lebih banyak memainkan peranannya sebagai sebuah badan koordinasi dibandingkan sebagai sebuah organisasi internasional yang mandiri. Hal ini disebabkan karena banyak perjanjian internasional yang dibuat oleh ASEAN lebih mencerminkan sebagai sebuah perjanjian multilateral antara negara-negara anggotanya dan ASEAN hanya sebagai “penontonnya” saja.

b. Pembuatan Perjanjian Internasional oleh ASEAN Setelah Berlakunya Piagam ASEAN

Sejak diberlakukannya Piagam ASEAN terutama dengan tercantumnya Pasal 3 juncto Pasal 41 ayat (7), ASEAN serasa menemukan jati dirinya sebagai sebuah organisasi internasional. Dalam ketentuan tersebut dapat diketahui bahwa ASEAN diberi mandat untuk melakukan (menandatangani) perjanjian dengan negara lain atau subyek hukum internasional lainnya. Hanya saja dalam ketentuan tersebut tidak dinyatakan secara tegas status dan kedudukan ASEAN. Masih terjadi pencampuradukan antara pengertian ASEAN sebagai sebuah organisasi internasional yang mandiri yang dibedakan dengan negara-negara anggotanya dan Pengertian ASEAN sebagai collective members. Dalam ketentuan tersebut prosedur pembuatan perjanjian internasional seperti yang dimaksud oleh pasal tersebut akan diatur lebih lanjut oleh Dewan koordinasi ASEAN melalui konsultasi dengan Dewan Komunitas ASEAN. Sebagaimana yang kita ketahui bahwa Dewan Koordinasi 
ASEAN adalah dewan yang terdiri dari para menteri luar negeri negaranegara anggota. Sedangkan Dewan Komunitas ASEAN adalah dewan yang terdiri dari Dewan Komunitas Politik dan Keamanan, Dewan Komunitas Ekonomi, Dewan Komunitas Sosial Budaya ASEAN yang semuanya dipegang oleh pejabat-pejabat tinggi yang relevan dari negaranegara anggotanya.

Dari kurun waktu tahun 1998 sampai dengan tahun 2011, ASEAN belum mempunyai prosedur pembuatan perjanjian internasional seperti yang dimaksud oleh Pasal 41 ayat (7) Piagam ASEAN. Prosedur pembuatan perjanjian internasional oleh ASEAN sebagai entitas yang mandiri dan dibedakan dari negara anggotanya telah berhasil dibuat pada tahun 2011 dengan dikeluarkannya 2011 Rules of Procedure for the Conclusion of International Agreements by ASEAN (selanjutnya disebut ROP). Adapun prosedur pembuatan perjanjian internasional oleh ASEAN sebagai collective members sampai saat ini belum ada pengaturannya secara jelas.

ROP diadopsi dalam pertemuan Dewan Koordinasi ASEAN IX pada tanggal 17 November 2011 di Bali, Indonesia (Anggarara Cininta P, 2012: hlm.92). Dalam aturan ini ASEAN sebagai sebuah entitas tersendiri yang dibedakan dengan negara anggotanya diberikan kewenangan untuk membuat perjanjian internasional dengan pihak lain, hal ini tertera dalam Pasal (Rule) I yang menyatakan bahwa, "these rules specify the procedure for the conclusion of international agreements by ASEAN as an intergovernmental organisation in the conduct of external relations as provided in article 41(7) of the ASEAN charter".

Merujuk pada isi ketentuan Pasal 2 ROP maka Perjanjian internasional yang tunduk pada ROP adalah perjanjian internasional yang memenuhi syarat-syarat sebagai berikut: 
1) Sebuah perjanjian tertulis

2) Dibuat untuk tujuan apapun

3) Diatur oleh hukum internasional

4) Menciptakan hak dan kewajiban bagi ASEAN sebagai entitas yang terpisah dan dibedakan dari negara-negara anggotanya.

Berdasarkan hal tersebut dapat diketahui bahwa sebuah perjanjian internasional yang dibuat oleh ASEAN haruslah sebuah perjanjian internasional yang dapat menciptakan hak dan kewajiban bagi ASEAN sebagai entitas yang terpisah dan dibedakan dari negara-negara anggotanya. Perjanjian ASEAN tersebut hanya dibuat untuk dan atas nama ASEAN sebagai sebuah organisasi internasional. Konsekuensi hukum dari ketentuan dan pernyataan tersebut adalah perjanjian internasional yang bersifat kolektif dari negara-negara anggota ASEAN tidaklah masuk dalam kategori ini dan perjanjian ASEAN sebagai sebuah organisasi mandiri tidak dapat berlaku mengikat secara langsung terhadap negara anggotanya.

Prosedur pembuatan perjanjian internasional oleh ASEAN sebagai entitas yang mandiri adalah sebagai berikut:

a. Sebelum dilakukan negosiasi atas suatu perjanjian internasional, pejabat senior Badan Kementerian Sektoral ASEAN yang relevan harus terlebih dahulu mengkkordinasikan proposal dengan Komite Wakil Tetap ASEAN;

b. Proposal tersebut kemudian diajukan dalam Pertemuan Para Menteri Luar Negeri Negara Anggota ASEAN, dan proposal tersebut dapat diterima atau ditolak;

c. Jika proposal tersebut diterima maka Pertemuan Luar Negeri Negara Anggota ASEAN dapat mengutus perwakilan tetap dari ASEAN untuk melakukan negosiasi atas nama ASEAN sebagai organisasi intergovernmental. Perwakilan tetap ini dapat dilakukan oleh Sekretaris 
Jenderal ASEAN yang ditunjuk dengan pemberian surat kuasa kepadanya;

d. Perwakilan ASEAN ang ditunjuk untuk melakukan negosiasi harus memberikan informasi mengenai perkembangan negosiasi kepada pejabat senior Badan Kementerian Sektoral dan Komite Wakil Tetap ASEAN;

e. Setelah proses negosiasi, perwakilan ASEAN tersebut membubuhkan parafnya pada draft perjanjian internasional semata-mata untuk menegaskan bentuk dan isi perjanjian teks perjanjian;

f. Selanjutnya draft yang telah dibubuhi paraf tersebut harus diajukan kepada pejabat senior Badan Kementerian Sektoral ASEAN yang relevan untuk disahkan;

g. Pengesahan tersebut dikonsultasikan dengan Komite Wakil Tetap ASEAN;

h. Komite Wakil Tetap ASEAN akan mengajukan pengesahan draft tersebut dalam Pertemuan Para Menteri Luar Negeri untuk meminta pertimbangan (Anggarara Cininta P, 2012: hlm. 95-96).

Berdasarkan Pasal 6 ROP, draft perjanjian internasional yang berhasil dibuat oleh perwakilan ASEAN tidak boleh diangggap sebagai sebuah "final text” dan harus tunduk pada ketentuan yang disyaratkan oleh Pasal 7. Oleh karenanya seorang perwakilan ASEAN dalam hal ini Sekretaris Jenderal ASEAN tidak boleh bertindak langsung mewakili ASEAN dan negara anggota ASEAN tetapi harus dikonsultasikan dengan Badan Kementerian Sektoral ASEAN dan Komite Tetap ASEAN.

Sebuah Perjanjian Internasional yang dibuat oleh ASEAN berdasarkan Pasal 8 ROP akan berlaku mengikat bagi ASEAN dengan dua cara yaitu dengan signature or an act of formal confirmation. Penandatanganan (signature) dilakukan oleh Perwakilan ASEAN apabila 1) perjanjian internasional yang bersangkutan menentukan bahwa penandatanganan akan 
memiliki efek tersebut, atau 2) ASEAN bermaksud agar tanda tangan memiliki efek tersebut yang tercermin dari surat kuasa (full power) yang diberikan kepada perwakilan ASEAN (Anggarara Cininta P, 2012: hlm.113). Adapun tindakan konfirmasi (act of formal confirmation) dilakukan apabila: 1) perjanjian internasional yang bersangkutan menentukan bahwa kesepakatan dinyatakan dengan cara tersebut, 2) maksud ASEAN untuk melakukan tindakan konfirmasi tercermin dalam surat kuasa atau dinyatakan dalam proses negosiasi atau 3) perwakilan ASEAN yang telah melakukan negosiasi, menandatangani perjanjian yang terhadapnya harus dilakukan tindakan konfirmasi (Anggarara Cininta P, 2012: hlm. 113).

Adapun pihak yang memiliki kewenangan untuk melakukan tanda tangan atau tindakan konfirmasi atas nama ASEAN akan ditentukan dalam pertemuan para menteri luar negeri ASEAN. Dalam hal ini pihak yang ditunjuk untuk mewakili kepentingan ASEAN berdasarkan ROP adalah Sekretaris Jenderal ASEAN atau pihak lain yang diangkat dalam Pertemuan Para Menteri Luar Negeri Negara Anggota ASEAN. Sedangkan yang dimaksud dengan "pihak yang diangkat" adalah Deputi Sekretaris Jenderal ASEAN atau Perwakilan dari Negara Koordinator yang diangkat berdasarkan Pasal 8 ayat (5) ROP. Negara koordinator adalah negara-negara anggota ASEAN yang secara bergantian bertanggung jawab sepenuhnya dalam mengkordinasikan dan memajukan kepentingan-kepentingan ASEAN dalam hubungannya dengan mitra-mitra wicara serta organisasi internasional lainny Anggarara Cininta P, 2012: hlm. 114).

\section{Status dan kekuatan Mengikat Perjanjian Internasional dihadapan ASEAN dan Negara Anggotanya}

Dalam Piagam ASEAN belum diatur secara jelas dan detail tentang status perjanjian internasional yang dibuat oleh ASEAN sebagai entitas yang mandiri terhadap negara-negara anggotanya. Aturan dan ketentuan tentang 
status perjanjian internasional yang dibuat ASEAN hanya ditemukan dalam Pasal 2 ROP yang menyebutkan bahwa Perjanjian Internasional yang dibuat oleh ASEAN hanya akan menciptakan hak dan kewajiban bagi ASEAN sebagai sebuah organisasi internasional yang mandiri dengan kata lain tidak akan menciptakan hak dan kewajiban bagi negara-negara anggotanya.

Dalam praktik dan kebiasaan di ASEAN memang tidak dikenal pendelegasian kewenangan dari negara anggota kepada ASEAN sebagai sebuah organisasi untuk bertindak untuk dan atas nama negara anggota. Selain itu terdapat prinsip-prinsip hukum internasional yang berkembang dan diterapkan dalam ASEAN dalam pembuatan perjanjian internasional yaitu sebagai berikut:

a. Prinsip Pacta Tertiis Nec Nocent Nec Prosunt

b. Prinsip Full Power For Expressing The Consent Of The State To Be Bound By A Ttreaty

c. Prinsip State Sovereignty

Berdasarkan Prinsip Pacta Tertiis Nec Nocent Nec Prosunt yang tersirat dalam Pasal 34 Konvensi Wina 1969 menjelaskan bahwa, “a treaty does not create either obligations or right for third state without consent”. Pernyataan yang sama tentang ketentuan tersebut juga dapat diketemukan dalam Pasal 34 Konvensi Wina 1986. Jika dalam hal ini negara anggota ASEAN dianggap sebagai pihak ketiga dalam pembuatan perjanjian, maka berdasarkan ketentuan tersebut maka perjanjian internasional yang dibuat oleh Sekretaris Jenderal ASEAN dengan pihak eksternal untuk dan atas nama anggota ASEAN tentu bertentangan dengan prinsip tersebut. Kemudian di dalam Prinsip Full Power for Expressing the Consent of the State to be Bound by a treaty ditegaskan bahwa jika suatu perjanjian ditandatangani oleh perwakilan negara maka perwakilan terebut harus mendapatkan full power. Sehingga jika suatu perjanjian internasional 
ditandatangani oleh Sekretaris Jenderal ASEAN tetapi mengikat negara anggotanya, maka Sekretaris Jenderal ASEAN harus memperoleh full power dari negara anggotanya (Damos Dumoli, 2010: hlm.57). Adapun praktik pemberian full power kepada organ asing tidak lazim dalam hukum perjanjian internasional (Damos Dumoli, 2010: hlm.57). Sedangkan jika dikaitkan dengan Prinsip Kedaulatan dan Yurisdiksi Negara, maka berdasarkan prinsip ini suatu negara tidak mungkin dapat meratifikasi perbuatan hukum subyek hukum internasional lain (Damos Dumoli, 2010: hlm.57).

Perjanjian internasional yang dibuat oleh ASEAN sebagai sebuah organisasi internasional dengan pihak eksternal agar dapat berlaku di negara anggotanya harus mendapatkan persetujuan/pengesahan/ratifikasi terlebih dahulu di masing-masing negara anggotanya. Berikut ini adalah perjanjian yang dibuat oleh ASEAN sebagai sebuah organisasi internasional dengan pihak lain yang membutuhkan persetujuan/pengesahan/ratifikasi terlebih dahulu dari negara anggotanya sebelum dapat berlaku mengikat di negara anggotanya:

a. ASEAN - China Memorandum of Understanding on Cultural Cooperation (Bangkok $3^{\text {rd }}$ August 2005), signed by the Secretary General of ASEAN;

b. Memorandum of Cooperation between the Department of Commerce of the United States of America and the Association of Southeast Asian Nations (ASEAN) Secretariat concerning Cooperation on Trade Related Standards and Conformance Issues ( $5^{\text {th }}$ April 2001), signed by the Secretary General of ASEAN;

c. Memorandum of Understanding between the Governments of the Member Countries of the Association of Southeast Asian 
Nations (ASEAN) Secretariat and the Ministry of Agriculture of the People's Republic of China on Agricultural Cooperation (Phnom Penh, $2^{\text {nd }}$ November 2002), signed by the Secretary General of ASEAN;

d. Memorandum of Understanding between the Governments of the Member Countries of the Association of Southeast Asian Nations (ASEAN) Secretariat and the Government of the People's Republic of China on Cooperation in the Field of Non-traditional Security Issues (Bangkok, 10 $0^{\text {th }}$ January 2004), signed by the Secretary General of ASEAN;

e. Memorandum of Understanding between the Governments of the Member Countries of the Association of Southeast Asian Nations (ASEAN) Secretariat and the Government of the People's Republic of China on Transport Cooperation (Vientiane, $27^{\text {nd }}$ November 2004), signed by the Secretary General of ASEAN;

f. Memorandum of Understanding between the Governments of the Member Countries of the Association of Southeast Asian Nations (ASEAN) Secretariat and the Ministry of Agriculture of the People's Republic of China on Agricultural Cooperation (Cebu, 14 ${ }^{\text {th }}$ January 2007), signed by the Secretary General of ASEAN (Damos Dumoli, 2011: hlm.20-21).

Selain contoh tersebut di atas, terdapat perjanjian internasional antara ASEAN sebagai sebuah organisasi dengan negara anggota (akan tetapi dalam hal ini diposisikan bukan sebagai negara anggota), perjanjian tersebut agar dapat berlaku dimasing-masing negara anggota ASEAN lainnya harus membutuhkan ratifikasi terlebih dahulu dari negara tersebut. Contoh perjanjian tersebut dapat diketahui dalam the 2009 Agreement on the 
Privileges and Immunities of the Association of Southeast Asian Nations yang dibuat oleh ASEAN sebagai sebuah organisasi internasional dan Indonesia (host state). Sampai saat ini perjanjian tersebut baru diratifikasi oleh tiga negara saja yaitu Singapura, Thailand dan Vietnam. Tanpa adanya ratifikasi full dari sepuluh negara anggota ASEAN maka agreement tersebut hanyalah berupa dokumen saja dan tidak mempunyai kekuatan hukum.

\section{Simpulan}

Berdasarkan Pasal 3 juncto Pasal 41 ayat (7) Piagam ASEAN, ASEAN mempunyai kewenangan hukum untuk membuat perjanjian internasional dengan pihak eksternal. Untuk tujuan ini harus dibedakan status ASEAN sebagai collective members atau sebagai sebuah organisasi internasional yang mandiri. Kewenangan hukum ASEAN sebagai collective members untuk membuat perjanjian internasional sampai saat ini belum ada aturan pelaksananya sedangkan sebagai sebuah organisasi internasional yang mandiri sudah diatur oleh the 2011 Rules of Procedure for the Conclusion of International Agreements by ASEAN. Dalam praktik, pelaksanaan kewenangan hukum ASEAN ini seringkali terhambat oleh kuatnya penerapan prinsip kedaulatan negara yang dianut oleh masing-masing negara anggota ASEAN dan juga karena masih lemahnya posisi dan kewenangan Sekretaris Jenderal ASEAN dihadapan negaranegara anggota ASEAN. Dengan kondisi ini menyebabkan ASEAN sebagai sebuah organisasi internasional yang mandiri dan dibedakan dari negara-negara anggotanya menjadi terbatas dalam menjalankan fungsi dan peranannya terutama ketika berhubungan dengan pihak eksternal.

\section{Daftar Pustaka}

Anggarara Cininta P. 2012. "Personalitas Hukum ASEAN terhadap Kedudukan ASEAN dalam Perjanjian yang dibuat dengan Negara atau Organisasi Internasional”, Skripsi, Jakarta: Fakultas Hukum Universitas Indonesia, Juli

2012, $\quad$ http://lontar.ui.ac.id/file?file=digital/20312700-S43214Personalitas\%20hukum.pdf, diakses tanggal 4 Desember 2013. 
Bambang Cipto. 2007. Hubungan Internasional di Asia Tenggara, Teropong terhadap Dinamika, Realitas, dan Masa Depan, Yogyakarta: Pustaka Pelajar.

Brownlie, Ian. 1998. Principles of Public International Law, Oxford: Clarendon Press.

Cassese, Antonio. 2005. International Law, Second Edition, United Kingdom: Oxford University Press.

Center for International Law, National University of Singapore, ASEAN Treaty, http://cil.nus.edu.sg/category-search/, diakses tanggal 23 Oktober 2013.

Center for International Law, National University of Singapore, ASEAN Treaty http://cil.nus.edu.sg/2012-memorandum-of-understanding-between-theassociation-of-southeast-asian-nations-and-the-asian-development-banksigned-on-4-april-2012-in-phnom-penh-cambodia diakses tanggal 12 Desember 2013.

Center for International Law, National University of Singapore, ASEAN Treaty, http://cil.nus.edu.sg/2011/2011-asean-plus-three-emergency-rice-reserveagreement-signed-on-7-october-2011-in-jakarta-indonesia/, diakses tanggal 12 Desember 2013.

Center for International Law, National University of Singapore, ASEAN Treaty, http://cil.nus.edu.sg/2010/2010-joint-declaration-on-asean-un-collaborationin-disaster-management/, diakses tanggal 12 Desember 2013.

Chalermpalanupap, Termsak. 2009. "the ASEAN Secretariat and Legal Issues Arising from ASEAN Charter”, Jurnal Hukum Internasional, Volume 6 Nomor 2, Januari 2009, Depok: Lembaga Pengkajian Hukum Internasional-Fakultas Hukum Universitas Indonesia.

Chesterman, Simon. 2010. "Does Asean Exist? The Association of Southeast Asian Nations as An International Legal Person", Singapore Year Book of International Law (SYBIL) Journal, Number 12, 2010, Singapore: the National University of Singapore.

Damos Dumoli. 2010. Hukum Perjanjian Internasional-Kajian Teori dan Praktik Indonesia, Bandung: PT.Refika Aditama.

--------------. 2011. “Treaty Making Power Asean Legal Analysis on Asean Practices", Paper dipresentasikan dalam the 2nd CILS International Conference on Asean's Role in Sustainable Development, 21 November 2011, Yogyakarta: Center for International Law Studies, Faculty of Law Universitas Indonesia in Cooperation with Faculty of Law Universitas Gadjah Mada.

Djauhari Oratmangun. 2009. "ASEAN Charter: A new Beginning for Southeast Asian Nations”, Jurnal Hukum Internasional, Volume 6 Nomor 2, Januari 2009, Depok: Lembaga Pengkajian Hukum Internasional-Fakultas Hukum Universitas Indonesia.

Eddy Pratomo. 2009. "Prospek dan Tantangan Hukum Internasional di ASEAN dan Indonesia Pasca Piagam ASEAN dari Sisi Perjanjian Internasional”, Jurnal Hukum UII, Volume 16 Nomor 1 Edisi Januari 2009, Yogyakarta: Fakultas Hukum Universitas Islam Indonesia. 
Elfia Farida. 2009. "Efektivitas Piagam ASEAN (ASEAN Charter) bagi ASEAN sebagai Organisasi Internasional”, Jurnal QISTIE, Volume 3 Nomor 3, 2009, Semarang: Fakultas Hukum Universitas Wahid Hasyim.

Fuat Albayumi. 2012. "Soft Law sebagai Sebuah Strategi: Studi Kasus Piagam ASEAN (ASEAN Charter)”, Jurnal Spektrum, Volume 12 Nomor 2, Juli 2012, Semarang: Fakultas Ilmu Sosial dan Ilmu Politik Universitas Wahid Hasyim.

Garner, Bryan A., 2004, Black’s Law Dictionary, edition 8, Minnesota: West Publishing.

Guan, Benny Teh Cheng, “ASEAN's Regional Challenge: the ASEAN Process”, the Copenhagen Journal of Asian Studies, Volume 20, 2004, Denmark: Asia Research Center-Copenhagen Business School.

Interpretation of the Agreement of 25 March 1951 between the WHO and Egypt, Advisory opinion, ICJ Rep.1980

Kementerian Luar Negeri Republik Indonesia, 2008, ASEAN Selayang Pandang, Jakarta.

QC, Malcom N. Shaw, 2003, International Law, Fifth Edition, United Kingdom: Cambridge University Press.

Schermers, Henry G. and M.Blokker, Niels, 2003, International Institutional Law, Fourth Revised Edition, Boston/Leiden: Martinus Nijhoff Publishers.

Sumaryo Suryokusumo. 1990. Hukum Organisasi Internasional, Jakarta: Penerbit Universitas Indonesia.

Weissberg, Guenter, 1961, the International Status of the United Nations, New York: Oceania Publication, Inc.

ASEAN Charter.

The Rules of Procedure for the Conclusion of International Agreements by ASEAN. 